Article

\title{
Study on Magnetic Abrasive Finishing Combined with Electrolytic Process-Precision Surface Finishing for SUS 304 Stainless Steel Using Pulse Voltage
}

\author{
Baijun Xing ${ }^{1}\left(\mathbb{D}\right.$, Yanhua Zou ${ }^{2, *(\mathbb{D})}$ and Masahisa Tojo ${ }^{1}$ \\ 1 Graduate School of Engineering, Utsunomiya University, 7-1-2 Yoto, Utsunomiya 321-8585, Tochigi, Japan; \\ xingbaijun@gmail.com (B.X.); mc206742@cc.utsunomiya-u.ac.jp (M.T.) \\ 2 School of Engineering, Course of Mechanical Engineering Systems, Utsunomiya University, 7-1-2 Yoto, \\ Utsunomiya 321-8585, Tochigi, Japan \\ * Correspondence: yanhua@cc.utsunomiya-u.ac.jp; Tel./Fax: +81-28-689-6057
}

check for updates

Citation: Xing, B.; Zou, Y.; Tojo, M. Study on Magnetic Abrasive Finishing Combined with Electrolytic Process-Precision Surface Finishing for SUS 304 Stainless Steel Using Pulse Voltage. J. Manuf. Mater. Process. 2022, 6, 14. https://doi.org/ 10.3390/jmmp6010014

Academic Editors: Swee Hock Yeo and Arun Prasanth Nagalingam

Received: 29 December 2021

Accepted: 16 January 2022

Published: 19 January 2022

Publisher's Note: MDPI stays neutral with regard to jurisdictional claims in published maps and institutional affiliations.

Copyright: (C) 2022 by the authors. Licensee MDPI, Basel, Switzerland. This article is an open access article distributed under the terms and conditions of the Creative Commons Attribution (CC BY) license (https:// creativecommons.org/licenses/by/ $4.0 /)$.

\begin{abstract}
In order to further study the Magnetic Abrasive Finishing with Electrolytic (EMAF) Process, we attempted to use rectangular wave pulse voltage for EMAF processing of SUS304 stainless steel, and the finishing characteristics were analyzed based on the experimental results in this paper. The EMAF process has been studied for years, but the study of Magnetic Abrasive Finishing with the. Pulse Electrolytic (P-EMAF) process has not been published. Therefore, in this study, the finishing characteristics of the P-EMAF process corresponding to different frequencies $(1 \mathrm{~Hz}, 10 \mathrm{~Hz}, 100 \mathrm{~Hz}$, $1 \mathrm{kHz})$ and duty ratios $(25 \%, 50 \%, 75 \%)$ are explored. The evaluation of the P-EMAF processing includes the surface roughness (SR) and the amount of material removal (MR); the surface of the workpiece was also observed by an optical microscope before and after processing. After analyzing the experimental results of P-EMAF processing, a set of comparative experiments between P-EMAF processing and MAF processing was carried out. In this study, when the $U_{r m s} 6 \mathrm{~V}$ pulse voltage of rectangular wave with $1 \mathrm{~Hz}$ and duty ratio $50 \%$ was used, a better processing result could be obtained. The processing efficiency of the P-EMAF process was also higher than that of the MAF process under the same experimental conditions.
\end{abstract}

Keywords: pulse voltage; EMAF; MAF; precision finishing; surface roughness

\section{Introduction}

Precision parts with high surface quality have played an important role in the development of science and technology. Magnetic Abrasive Finishing (MAF) was proposed in order to improve the precision of workpiece surfaces, which is difficult for finishing by traditional grinding process [1,2]. The finishing tool magnetic brush is composed of magnetic particles attracting each other in the magnetic field. Therefore, the magnetic brush is a flexible finishing tool, and the magnetic particles can move against each other against attractive forces. With sufficient magnetic force, the magnetic brush can be formed between the surfaces of the complex shape workpiece and the magnetic pole [3,4]. Due to this feature, fine-grained magnetic particles and abrasives can be used to finish the tiny surface, which is difficult to process by traditional technology. In addition, the magnetic field has penetrating properties, and a magnetic brush can be formed in the cavity of a workpiece. Therefore, the MAF process can be used to finish the inner cavity of workpiece [5-7]. Due to the advantages of the magnetic finishing tool, the MAF process is widely used in industrial fields that require precision finishing [1-8]. However, the flexible magnetic finishing tool also has disadvantages-insufficient finishing efficiency is one of the factors that affect its large-scale promotion. In order to improve finishing efficiency and retain the precision finishing characteristics of the MAF process, the magnetic abrasive finishing combined with the electrolytic (EMAF) process was proposed [9]. 
The proposal of the EMAF process aims to maximize the processing advantages of the MAF and electrolytic processes. For example, both processes belong to non-traditional machining technology, and both can be used to process special-shaped surfaces. Taking advantage of the processing characteristics of electrochemical dissolution of the electrolytic process, the processing efficiency is related to the current density in the electrolyte and has nothing to do with the strength and toughness of the material itself [10-14]. However, the processing accuracy of the electrolytic process is insufficient, the discharge area is difficult to accurately control, and the processed surface is prone to pitting corrosion which in turn affects the surface quality [15-17]. Therefore, if the high precision finishing characteristics of the MAF process are combined with the high efficiency of the electrolytic process, an efficient and high-precision surface finishing process will be obtained. At the same time, the processing advantages are used to complement the processing disadvantages in the EMAF process. In order to make the EMAF process be widely used, after exploring the machining characteristics of SUS304 stainless steel [18], the feasibility of using the EMAF process to finish the surface of aluminum alloy A5052 was proved [19].

In order to further study the processing characteristics of the EMAF process, pulse voltage was considered being used for EMAF processing in this study. Based on the principles of pulse electrolysis, it was confirmed to achieve high precision and superior surface quality in pulse electrochemical machining $[20,21]$. However, the study using pulse voltage for EMAF processing was not published. Thus, this paper aims to explore the feasibility of Magnetic Abrasive Finishing with the Pulse Electrolytic Process (P-EMAF) for the finishing of SUS 304 stainless steel plates, and based on the analysis of the experimental results, the machining mechanism is discussed. Furthermore, another verification experiment is designed to verify the previous inference.

\section{Processing Principle}

\subsection{Principle of EMAF Process}

The EMAF processing principle is shown in Figure 1. During the processing, the workpiece and the compound processing tool are connected to the anode and cathode of the power supply, respectively. The compound processing tool consists of four magnetic poles (arranged in the same direction) and a cross electrode. During EMAF processing, both the workpiece and the electrode surface are immersed in the electrolyte. The workpiece surface is finished by the rotation of the compound processing tool and the horizontal feed movement of the X-Y stage. The voltage and current values during processing are displayed by an oscilloscope or data logger, and the electrolyte temperature is measured by a PT100 sensor.

During EMAF processing, the electrolytic process and the MAF processing act on the workpiece surface at the same time as the electrode and the magnetic poles rotate together. The electrolytic process that is compounded into the EMAF process is used to efficiently flatten the surface protrusions, and the MAF process is used to further finish the surface of the workpiece. The processing efficiency of the EMAF process is higher than the traditional MAF process due to the processing efficiency of the electrolytic reaction, which is very efficient and not affected by the hardness of the material [14,22]. Since the MAF process that compounded into the EMAF process is mainly used to remove the passive film produced by the electrolytic process and the final surface finishing, the characteristics of the EMAF process not only retains the characteristic of high processing efficiency of the electrolytic reaction but also retains the high finishing precision of the MAF process. In this study, rectangular wave pulse voltage was used for P-EMAF processing. 


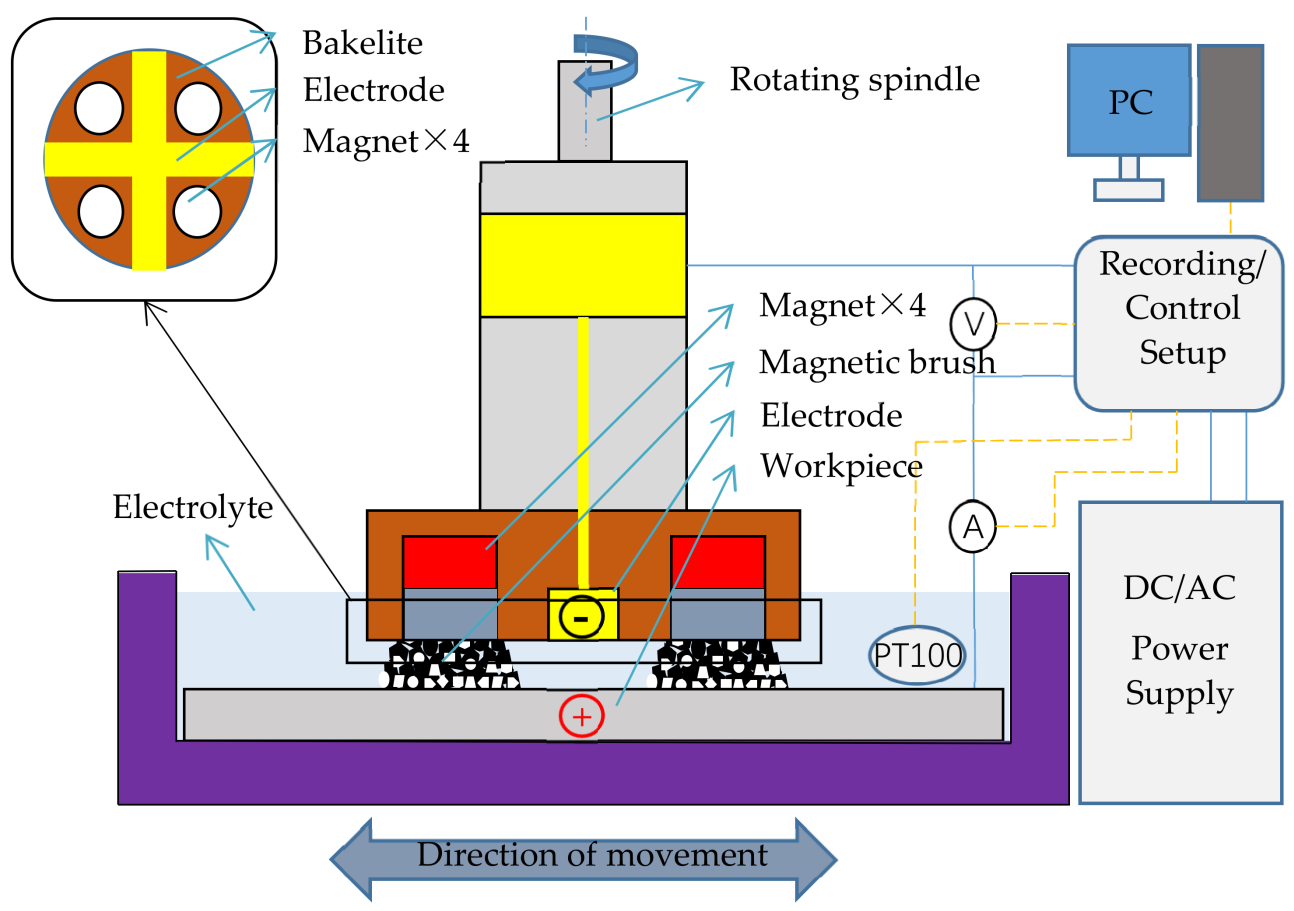

Figure 1. Schematic of EMAF processing principle.

During the P-EMAF processing, the amount of material removal of electrolytic reaction is shown in Equation (1). In the Equation, $m$ is the amount of material removal, $\eta$ is the current efficiency coefficient, I is the current value $(\mathrm{A}), \mathrm{t}$ is the energization time (s), $\mathrm{A}$ is the atomic weight, $\mathrm{F}$ is the faraday constant $(96500 \mathrm{C})$, and $\mathrm{n}$ is the valence of the electrolysis product $[23,24]$.

$$
\mathrm{m}=\eta \frac{\mathrm{ItA}}{\mathrm{Fn}}(\mathrm{g})
$$

\subsection{Principle of Electrolysis in P-EMAF Process}

In this study, neutral sodium nitrate aqueous solution is selected as the electrolyte. When the pulse voltage is on high-level voltage (on time), the main electrolytic reactions that occur during the P-EMAF process are shown in Equations (2) and (3), [25].

The main electrolytic reaction that occurs on the surface of the cathode:

$$
2 \mathrm{H}^{+}+2 \mathrm{e}^{-} \rightarrow \mathrm{H}_{2} \uparrow,
$$

Metal dissolution reaction of workpiece (anode):

$$
\mathrm{Me} \rightarrow \mathrm{Me}^{\mathrm{n}+}+\mathrm{ne}^{-},
$$

\subsection{Principle of $M A F$ Process}

During MAF processing, the magnetic brush formed between the surfaces of the magnetic pole bottom and the workpiece is used as a machining tool to finish the workpiece. The magnetic force $\mathrm{F}$ experienced by a single iron powder in a magnetic field can be decomposed into a force $F_{x}$ (along the direction of the magnetic force) and $F_{y}$ (along the direction of the magnetic equipotential line), as shown in Equations (4) and (5) [26,27].

$$
\begin{aligned}
& F_{x}=V \chi \mu_{0} H(\partial H / \partial x), \\
& F_{y}=V \chi \mu_{0} H(\partial H / \partial y),
\end{aligned}
$$


where $V$ is the volume of magnetic particles, $\chi$ is the magnetic susceptibility of magnetic particles, $\mu_{0}$ is vacuum permeability, $H$ is the magnetic field intensity, and $\partial H / \partial x$ and $\partial H / \partial y$ are the gradient of magnetic field intensity in $x$ and $y$ directions, respectively.

\subsection{Root-Mean-Square Voltage in P-EMAF Processing}

In a pulse period, the larger the pulse width (higher duty cycle), the longer the current working time; therefore, Root-Mean-Square voltage $\left(U_{r m s}\right)$ is used in this experiment when exploring pulse voltages with different pulse widths. In this study, a rectangular wave was selected to explore the feasibility of P-EMAF processing. The schema of the $U_{r m s}$ of the rectangular wave in this study is shown in Figure 2a and Equation (6), respectively [28,29].

$$
U_{r m s}=\sqrt{\frac{1}{T} \int_{0}^{T} u^{2} t d t}
$$

where $T$ is a pulse period, $\tau$ is the pulse width of one pulse period, $U_{m}$ is the high-level voltage, and $U_{r m s}$ is Root-Mean-Square voltage.

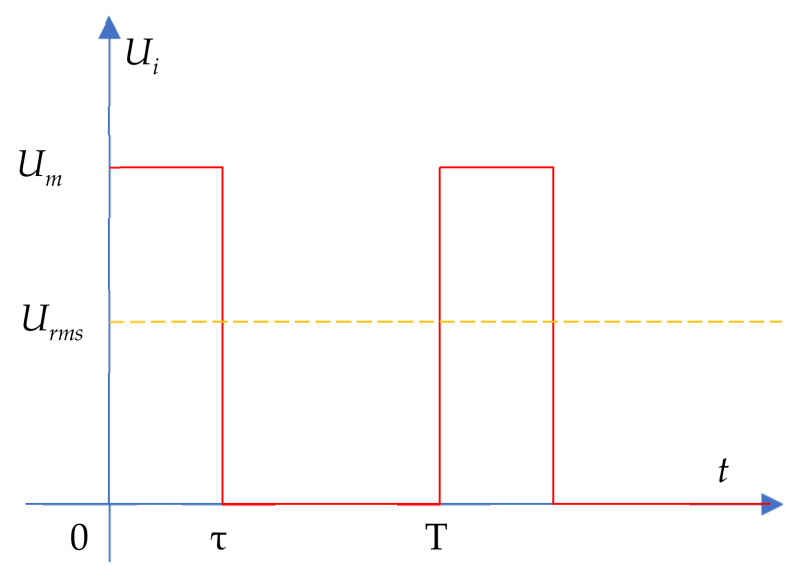

(a)

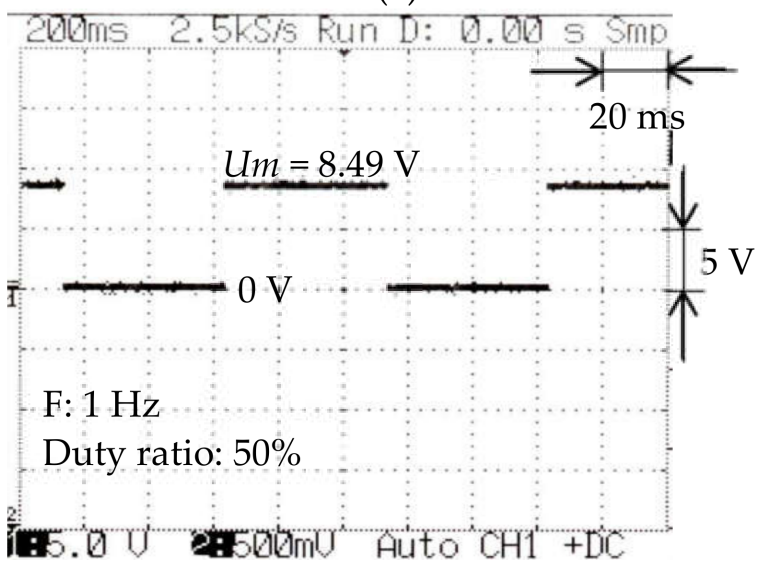

(c)

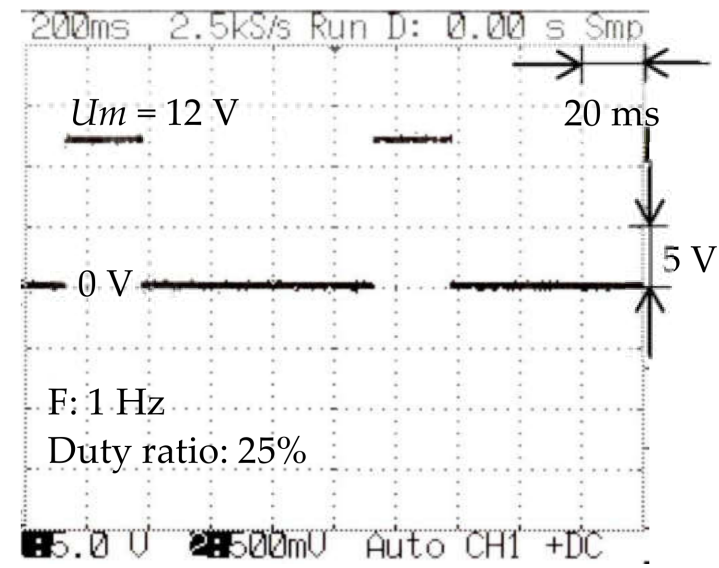

(b)

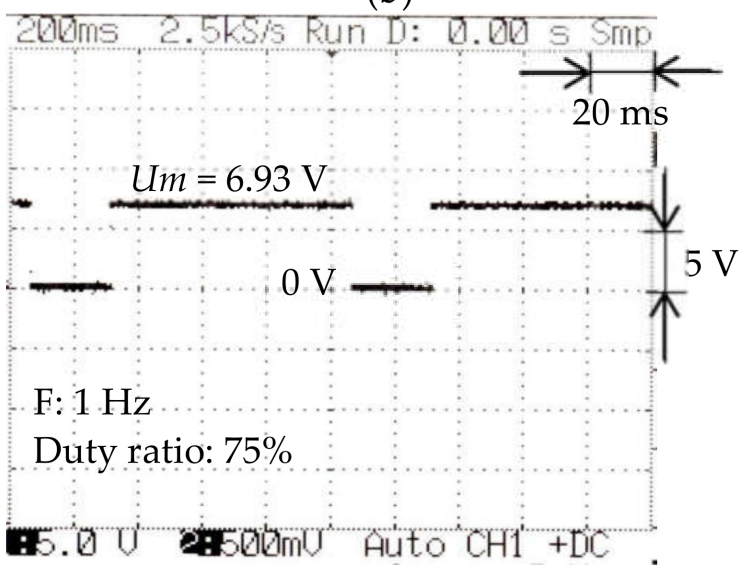

(d)

Figure 2. The schematic and actual rectangular wave voltage. (a) schematic diagram; (b) measured rectangular wave voltage when duty ratio is $25 \%$; (c) measured rectangular wave voltage when duty ratio is $50 \%$ and (d) measured rectangular wave voltage when duty ratio is $75 \%$. 
In this study, the low-level voltage is $0 \mathrm{~V}$ and the pulse width $(\tau)$ is $\frac{1}{4} \mathrm{~T}, \frac{1}{2} \mathrm{~T}$, and $\frac{3}{4} \mathrm{~T}$, respectively. According to Equation (6), when the $\tau$ is $\frac{1}{4} \mathrm{~T}, \frac{1}{2} \mathrm{~T}$, and $\frac{3}{4} \mathrm{~T}$, the relationship between $U_{r m s}$ and $U_{m}$ is shown in Equations (7)-(9), respectively.

$$
\begin{gathered}
U_{r m s}=\frac{1}{2} U_{m}, \tau=\frac{1}{4} \mathrm{~T} \\
U_{r m s}=\frac{1}{\sqrt{2}} U_{m}, \tau=\frac{1}{2} \mathrm{~T} \\
U_{r m s}=\frac{\sqrt{3}}{2} U_{m}, \tau=\frac{3}{4} \mathrm{~T}
\end{gathered}
$$

According to Equations (7)-(9), using pulse voltage with a root-mean-square voltage of $6 \mathrm{~V}$, when the duty ratio is $25 \%, 50 \%$, and $75 \%$, the corresponding maximum voltage $U_{m}$ is $12 \mathrm{~V}, 8.49 \mathrm{~V}$, and $6.93 \mathrm{~V}$, respectively. The measured values of the rectangular wave voltage used for processing are shown in Figure $2 b-d$, respectively.

\section{Experimental Setup and Compound Processing Tool}

\subsection{EMAF Processing Setup}

In order to explore the processing characteristics of the P-EMAF process, the experimental setup was modified to enable P-EMAF processing. The P-EMAF External view of the experimental setup is shown in Figure 3. The processing area mainly contains the vertical milling machine, $\mathrm{X}-\mathrm{Y}$ stage, compound processing tool, and $\mathrm{Pt} 100$ sensor. The start and stop of the spindle rotation and the stop of the $\mathrm{X}-\mathrm{Y}$ stage are controlled by a single-chip microcomputer and its attached drive circuit. In addition, the output voltage of the DC power supply is controlled by the single-chip microcomputer and a Frequency-Voltage conversion module. The output waveform of the AC power supply is programmed by a computer, and the frequency and maximum voltage are achieved by setting the power supply. In addition, by programming the single-chip microcomputer, the processing requirements of different stages are met and the semi-automatic processing is realized.

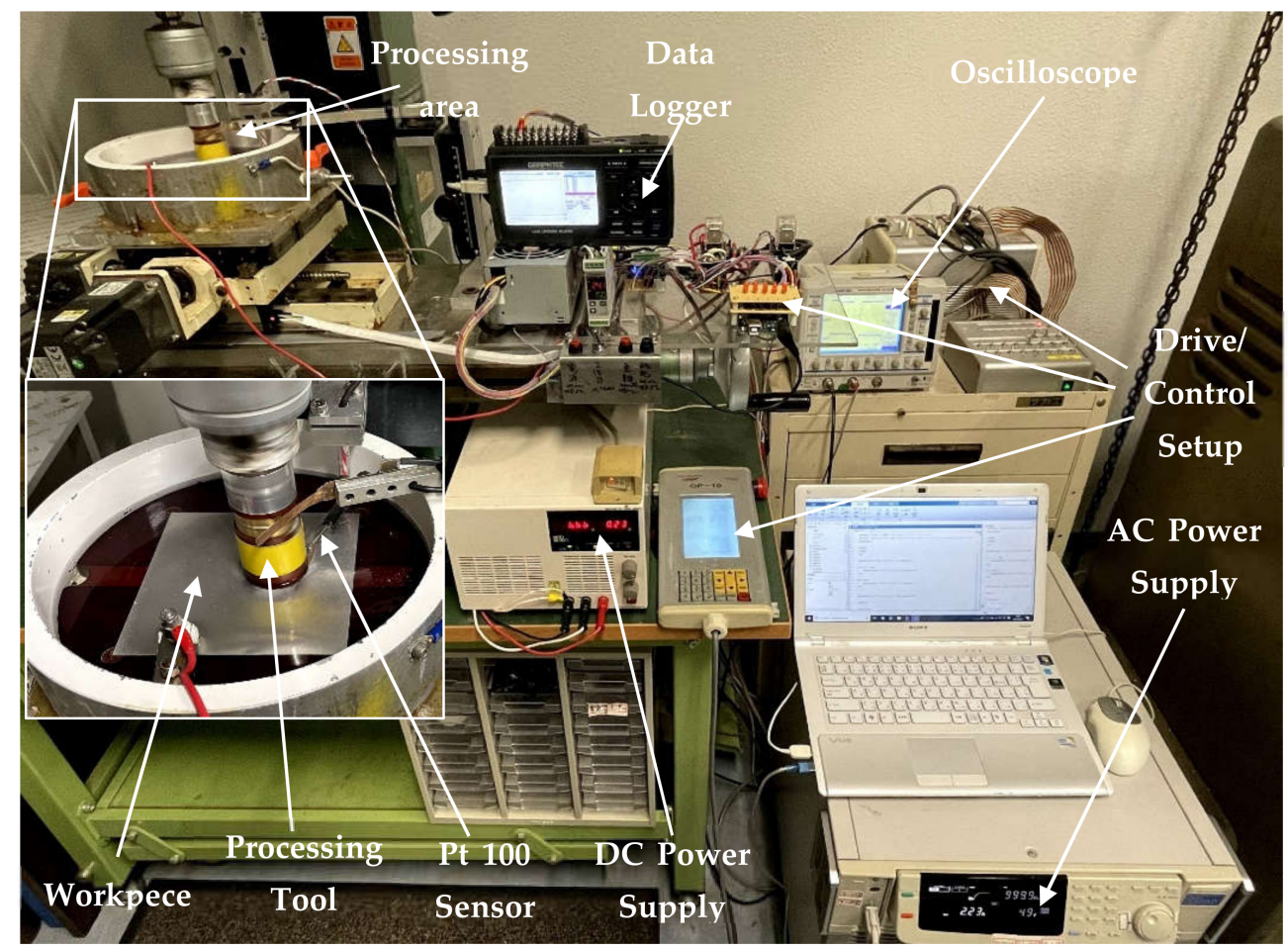

Figure 3. External view of experimental setup. 


\subsection{Schematic of EMAF Processing Set Up}

The schema of the EMAF setup is shown in Figure 4. As shown in the schematic diagram, the drive, and control device mainly integrate control modules such as a singlechip microcomputer, drive, relay, frequency to voltage conversion module, and programmer of X-Y stage, etc. The start and stop of the spindle, the stop of the X-Y stage, voltage output of DC-power supply, and ON/OFF of the AC-power supply are controlled during the processing by program. Because pulse voltage is used for P-EMAF processing, the high-frequency range that cannot be recorded by a data logger, the pulse voltage and current are displayed by a dual-channel oscilloscope. The temperature of the electrolyte during processing is monitored by a PT100 temperature sensor, and the temperature value is displayed by the indicator and recorded by the data logger. By compiling the program, the processing requirements of different stages can be controlled by a single-chip microcomputer.

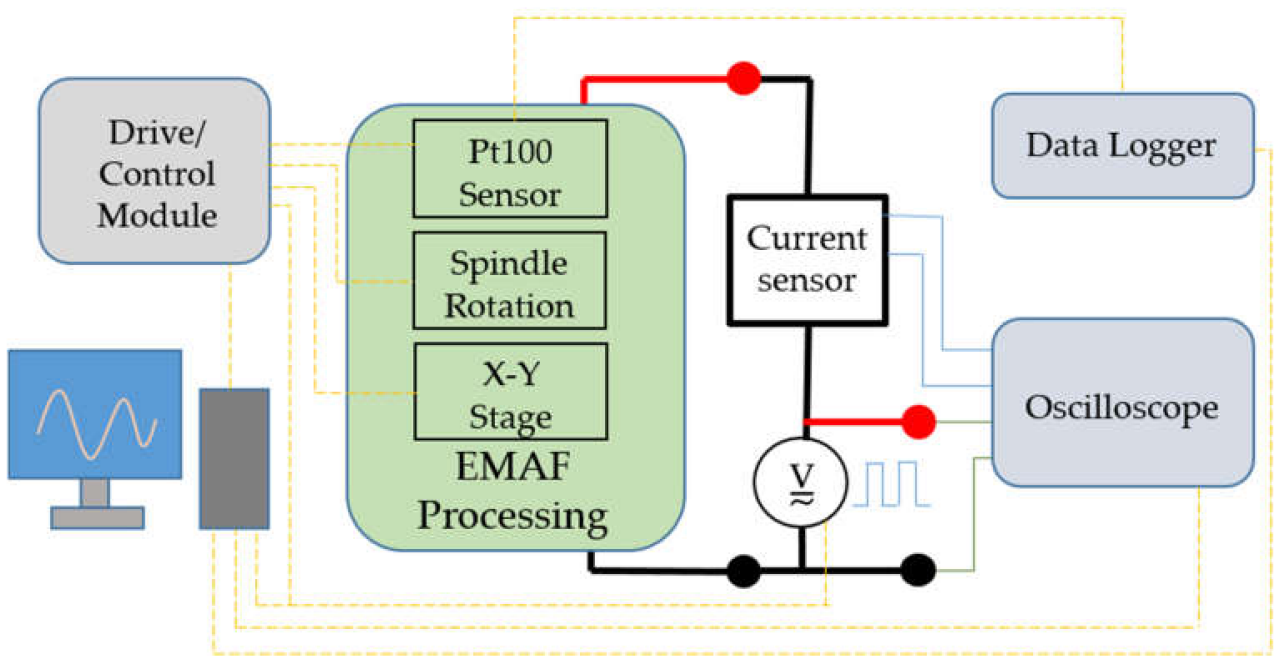

Figure 4. Schematic of P-EMAF processing set up.

\subsection{Simulation of Magnetic Induction}

The simulation results are shown in Figure 5. The software of MagNet (64-bit Version 2020.2.0.209) is used for the magnetic induction simulation in this study, and the results are mainly used to investigate the distribution of magnetic induction on the surface of processing tools and the workpiece. Since the different magnetic induction intensity will affect the shape of the magnetic brush and the finishing pressure, the reasonable design and layout of the compounded processing tool can be preliminarily determined based on the simulation results.

The magnetic induction on the processing tool surface is shown in Figure 5a. It can be seen from the simulation results that at the edges of magnetic poles the magnetic induction is the largest. The magnetic induction is also slightly weaker on the middle part of the magnetic pole surface. The magnetic induction outside the magnetic pole debilitates rapidly. If the magnetic induction is not strong enough, the magnetic brush will not provide enough finishing pressure. Figure $5 \mathrm{~b}$ shows the magnetic induction on the workpiece surface when the working gap is $1 \mathrm{~mm}$. It can be seen from the simulation results that the magnetic induction on the workpiece surface is obviously weaker than that on the processing tool surface. According to Equations (4) and (5), the finishing pressure provided by the magnetic brush is greater when it is closer to the processing tool. 


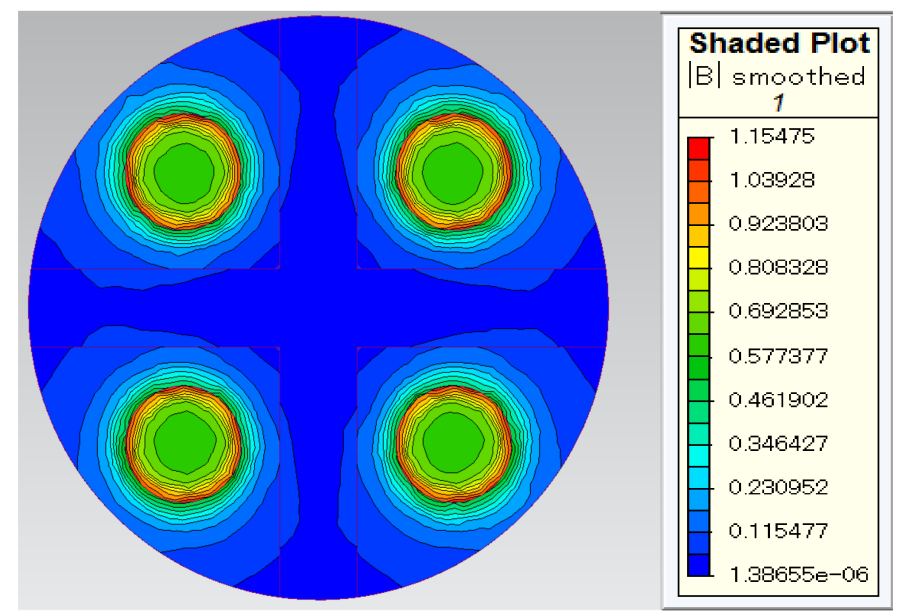

(a)

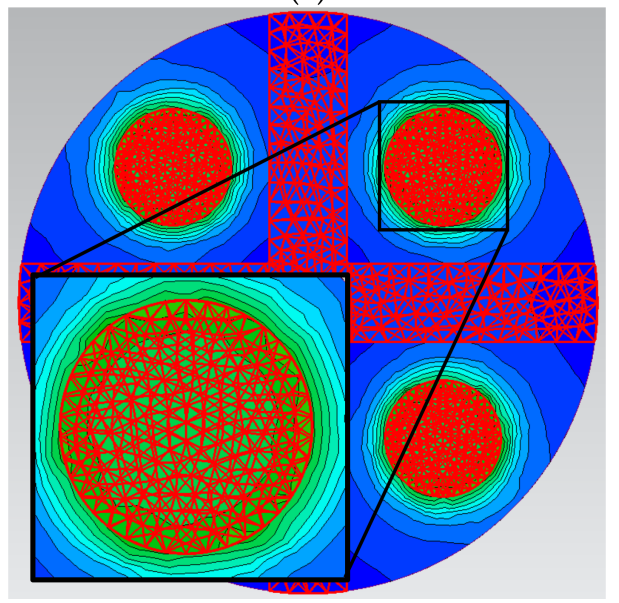

(c)

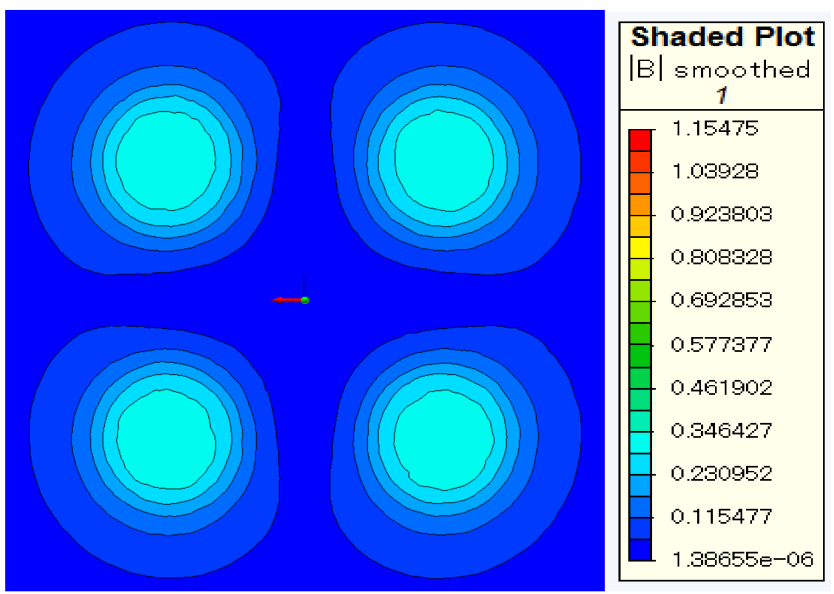

(b)

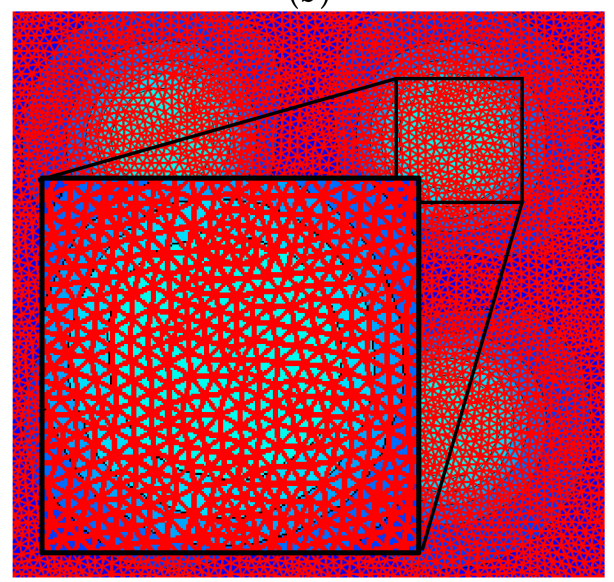

(d)

Figure 5. Simulation of magnetic induction. (a) magnetic induction on the surface of processing tools; (b) magnetic induction on the surface of the workpiece (working gap $1 \mathrm{~mm}$ ); (c) mesh of magnetic pole and electrode; (d) mesh of workpiece.

The mesh structure of the magnetic poles and electrode is shown in Figure $5 \mathrm{c}$. The mesh size of the magnetic pole is $0.5 \mathrm{~mm}$. Because the copper electrode is a non-magnetic material, it basically has no effect on the magnetic field distribution, and the mesh size is set to $1 \mathrm{~mm}$. Figure $5 \mathrm{~d}$ shows the mesh structure of the workpiece, and the mesh size is $0.5 \mathrm{~mm}$.

\section{Experimental Conditions and Results}

The feasibility of finishing SUS304 stainless steel and aluminum alloy A5052 by EMAF processing using the DC voltage has been proven $[9,19]$. After the EMAF processing mechanism of finishing SUS304 stainless steel has been further studied [18], the excessive amount of iron powder that can cause the occurrence of short circuits was clarified. When the working gap is $1 \mathrm{~mm}$, the limit amount of iron powder is $0.6 \mathrm{~g}$. Neutral electrolyte $\left(\mathrm{NaNO}_{3}\right)$ was selected as the electrolyte and SUS 304 stainless steel plane plate was selected as the workpiece. Based on the experimental results, the feasibility and finishing performance under different experimental conditions of P-EMAF processing are analyzed in this part.

\subsection{MAF Experimental Conditions and Results}

The surface roughness value is measured by the needle roughness tester (Mitutoyo SV-624-3D). The surface morphology observation before and after finishing by metallur- 
gical microscope (OLYMPUS BX51M) and the photos were recorded by a digital camera (SONY BX100).

The measurement area is shown in Figure 6, and the white part is the processing area. The measurement area of the surface roughness value is between two vertical red double-dotted lines. The measurement start position starts from the red double-dotted line on the left. The measurement direction of the surface roughness is along the black double-dotted line. There are three measurement positions, which are the centerline along the finishing feed direction and the centerline offset by $\pm 10 \mathrm{~mm}$. The average value is used as the final result. The surface observation position is shown in the blue area in the figure. There are three observation positions; in this paper, the surface topography of position two is used for analysis.

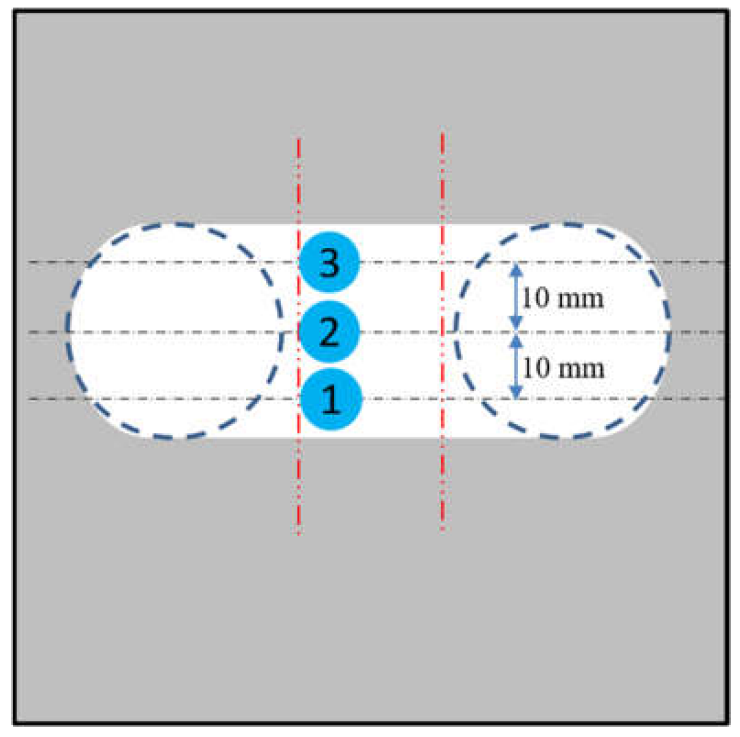

Figure 6. Surface roughness and topography measurement location.

The MAF process plays an important role in removing the passive film and reducing the surface roughness during EMAF processing. If the finishing capacity of the MAF process is not enough, the passive film will remain on the surface of the workpiece, which will cause an uneven surface. Therefore, it is very important to explore the finishing characteristics of the MAF process before determining the compound processing parameters. The MAF experimental conditions are shown in Table 1. Electrolytic iron powders of $330 \mu \mathrm{m}$ were selected as magnetic particles, and the amount of iron powder is $0.6 \mathrm{~g}$, and the finishing time of each stage is $10 \mathrm{~min}$. WA\#6000, WA\#8000, WA\#10000, and WA\#20000 were selected as abrasives, respectively.

Table 1. Experimental conditions of MAF process.

\begin{tabular}{cc}
\hline Item & Experimental Conditions \\
\hline Workpiece & SUS 304 stainless steel plane $(100 \times 100 \times 1 \mathrm{~mm})$ \\
Electrolytic iron powders & $330 \mu \mathrm{m}, 0.6 \mathrm{~g}$ \\
Abrasives particles & WA\#6000, WA\#8000, WA\#10000, WA\#20000 \\
Cutting fluid & Oily \\
Working gap & $1 \mathrm{~mm}$ \\
Stage feed speed & $5 \mathrm{~mm} / \mathrm{s}$ \\
Tool rotation speed & $450 \mathrm{rpm}$ \\
Processing time & $10 \mathrm{~min} / \mathrm{stage}$ \\
\hline
\end{tabular}

The results of the MAF experiment when using 330-micrometer electrolytic iron powder are shown in Figure 7. When the 330-micrometer electrolytic iron powder is used 
for MAF processing, all four types of abrasive have the largest change rate of surface roughness value in the first stage. From the second stage, the change rate of surface roughness value slows down. From the surface roughness value of each stage, the surface roughness value change law of WA\#8000 and WA\#20000 types of abrasive is relatively close. The WA\#6000 and WA\#10000 types of abrasive have a relatively close surface roughness value. However, the difference in average surface roughness values of the four abrasives after finishing is not large. Moreover, after $40 \mathrm{~min}$ of finishing, the final surface roughness values of the four types of abrasives are close to each other.

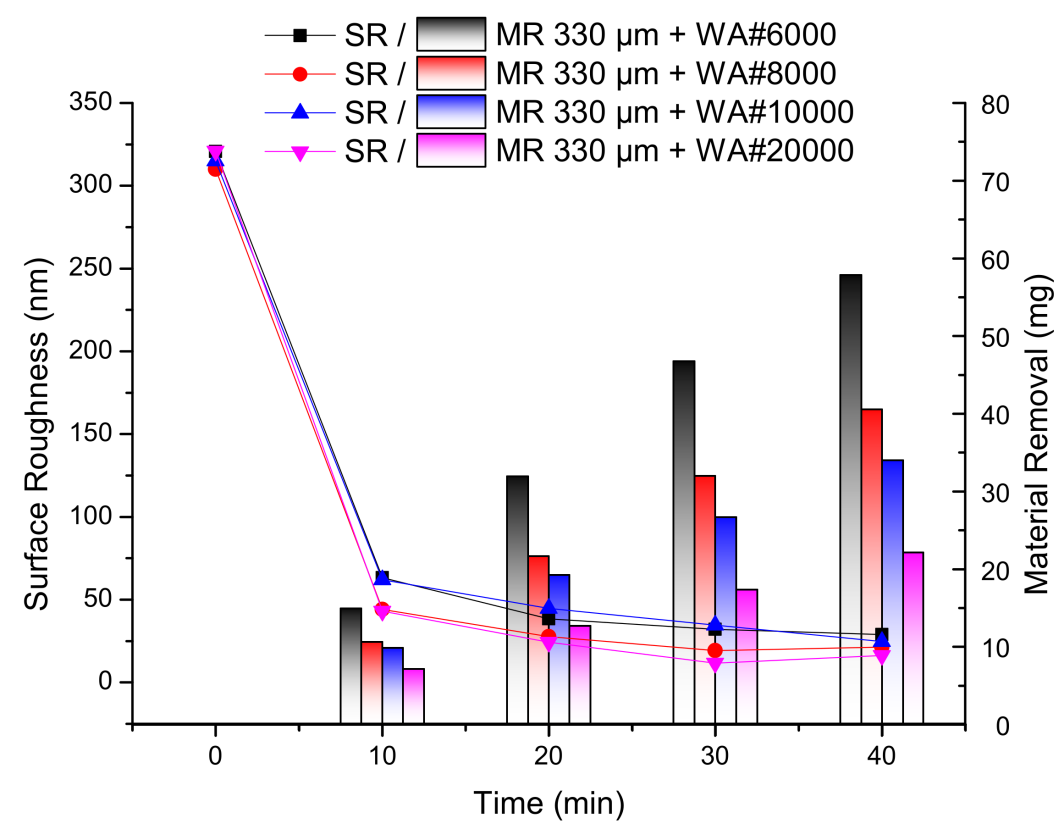

Figure 7. MAF process experimental results (330 $\mu \mathrm{m}$ electrolytic iron powder).

From the experimental results of material removal, WA\#6000 type has the highest material removal rate, followed by WA\#8000, and WA\#10000 is less than WA\#8000. Among the four types of abrasives, the WA\#20000 abrasives have the lowest material removal rate. In addition, as the finishing progresses, the difference in the material removal of the four types of abrasive becomes larger.

In order to understand the surface changes before and after finishing more intuitively, an optical microscope was used to observe the workpiece surface before and after finishing, the results of which are shown in Figure 8.

Figure 8 shows the surface morphology measured at position two before and after different stages of finishing. From the surface morphologies, the surface before finishing is relatively rough, and deep and shallow grooves exist. When the WA\#6000 abrasive is used for MAF processing, only the finishing scratches and a deep groove remained after the first stage of MAF processing. After the second stage of finishing, there are only finishing scratches remaining on the surface. Because the particle size of the WA\#6000 abrasive is relatively large, the processing traces are relatively rough. When the WA\#8000 abrasive is used, after the second stage of finishing, only a few deep grooves remained on the surface, and the finishing scratches became smooth-smoother than when the WA\#6000 abrasive is used. When the WA\#10000 abrasive is used, as finishing progresses, the surface will become smoother; the deep grooves on the surface cannot completely be removed until the fourth stage of finishing, but they are not obvious. When the WA\#20000 abrasive is used, the deep grooves remain on the surface and cannot be completely removed after the four-stage finishing, and the deep grooves are still obvious. Except for the remaining deep grooves, the surface becomes smooth, and the finishing traces are shallower than other types of abrasives. Based on the experimental results of surface roughness, material removal, and 
surface morphology, the type of WA\#8000 abrasive is selected for the following P-EMAF processing.
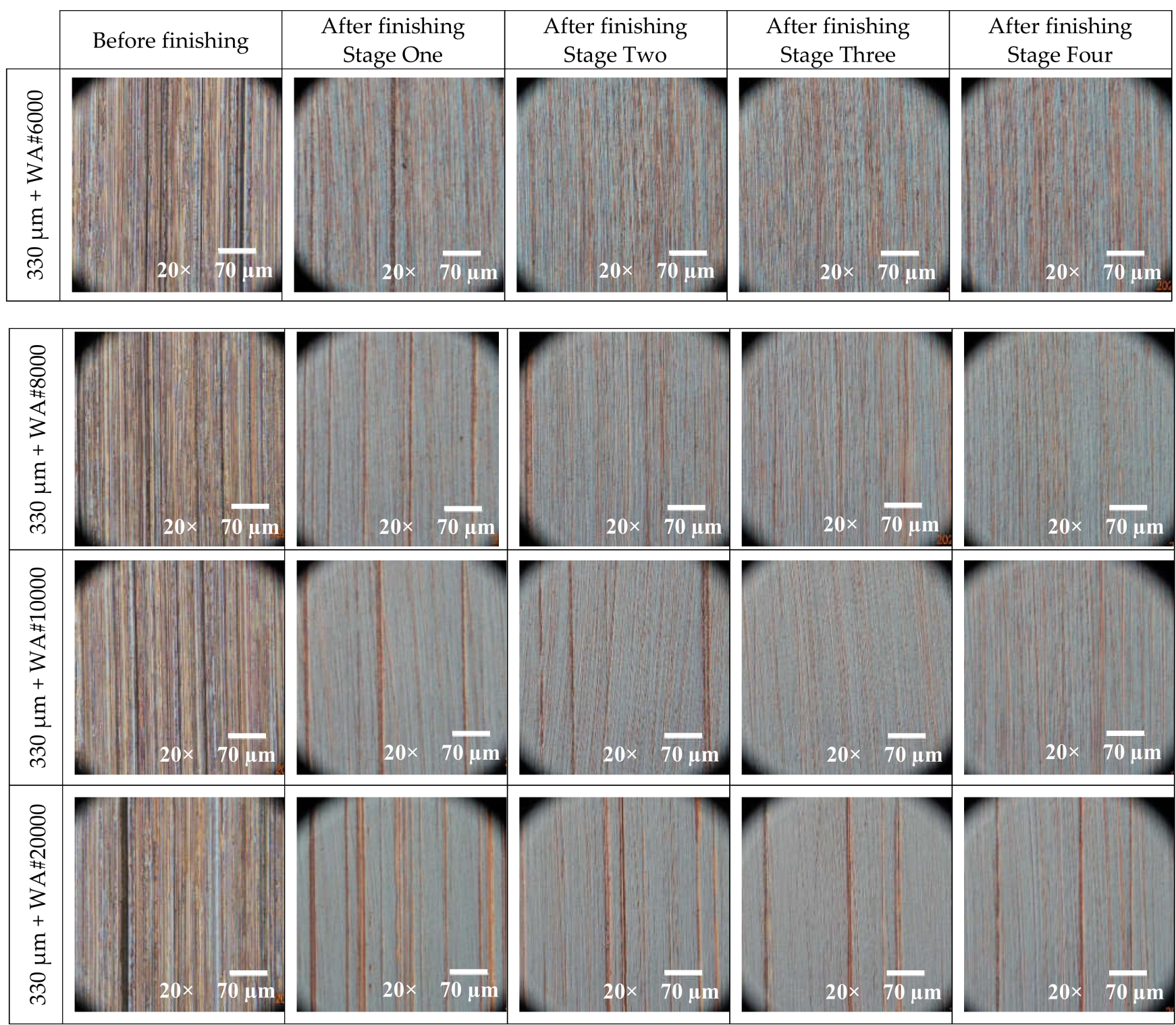

Figure 8. Surface morphology before and after finishing.

\subsection{P-EMAF Experimental Conditions and Results}

The P-EMAF experimental conditions are shown in Table 2. In the previous study, the maximum amount of iron powder is $0.6 \mathrm{~g}$ when the working gap is $1 \mathrm{~mm}[11,12]$. However, with the use of the compound processing tool, the surface of the magnetic pole will be worn, and the damage of the surface will affect the change of the magnetic field strength. Therefore, in order to avoid short-circuiting during processing and according to the current status of the compound processing tool, the amount of iron powder is reduced to $0.5 \mathrm{~g}$. 
Table 2. EMAF experimental conditions.

\begin{tabular}{cc}
\hline Item & Experimental Conditions \\
\hline Workpiece & SUS 304 stainless steel plane $(100 \times 100 \times 1 \mathrm{~mm})$ \\
Electrolytic iron powders & $330 \mu \mathrm{m}, 0.5 \mathrm{~g}$ \\
Abrasives particles & WA\# 8000 \\
Cutting fluid & Water soluble (EMAF), \\
Electrolyte & Oily (MAF) \\
NaNO $20 \% \mathrm{wt}$ \\
Root-mean-square voltage & $U_{r m s}=6 \mathrm{~V}$ \\
Voltage waveform & Rectangular wave \\
Duty ratio & $25 \%, 50 \%, 75 \%$ \\
& Duty ratio: $25 \%, U_{m}=12 \mathrm{~V}$ \\
High-level voltage $\left(U_{m}\right)$ & Duty ratio: $50 \%, U_{m}=8.49 \mathrm{~V}$ \\
& Duty ratio: $75 \%, U_{m}=6.93 \mathrm{~V}$ \\
Low-level voltage & $0 \mathrm{~V}$ \\
Frequency & $1 \mathrm{~Hz}, 10 \mathrm{~Hz}, 100 \mathrm{~Hz}, 1 \mathrm{kHz}$ \\
Working gap & $1 \mathrm{~mm}$ \\
Stage feed speed & $5 \mathrm{~mm} / \mathrm{s}$ \\
Tool rotation speed & $450 \mathrm{rpm}$ \\
Processing time & P-EMAF $(2 \mathrm{~min})+\mathrm{MAF}(8 \mathrm{~min})$ \\
\hline
\end{tabular}

The whole process is divided into two two-minute P-EMAF processing and eightminute MAF processing. The purpose of the first two-minute P-EMAF process is rapid flattening surface and preliminary finishing. In the next eight min, MAF processing is mainly used to remove the electrolysis products remaining on the surface and to further finish the surface.

When the rectangular wave pulse voltage frequency is $1 \mathrm{~Hz}$, the corresponding experimental results of different duty ratios are shown in Figure 9. From the experimental results, it can be seen that after two min of P-EMAF processing, the highest amount of material removal was obtained by using pulse voltage with a $1 \mathrm{~Hz}$ duty cycle of $25 \%$ compared to pulse voltages with a duty ratio of $50 \%$ and $75 \%$. At the same time, the surface roughness value corresponds to a duty ratio of $75 \%$ and $50 \%$ is better than that of duty ratio $25 \%$ because when the duty ratio is $25 \%$, the amount of material removed is larger and the electrolysis reaction is too violent, resulting in uneven electrochemical corrosion.

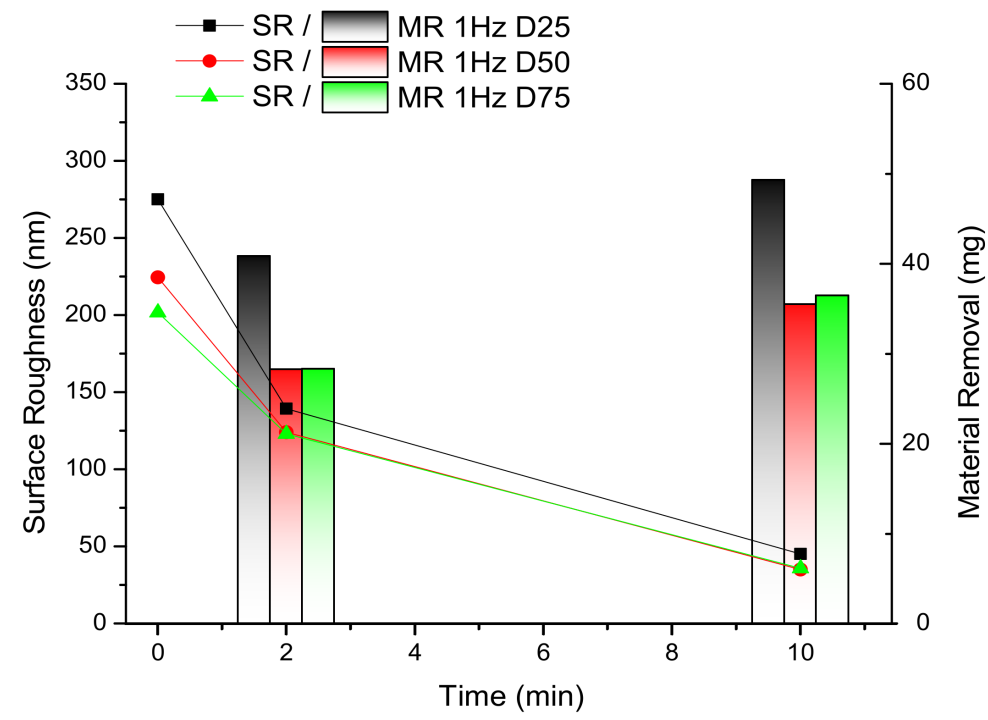

Figure 9. Experimental results when frequency is $1 \mathrm{~Hz}$.

After finishing the eight-minute MAF process, a relatively smooth surface is obtained. The final experimental results show that when the frequency is $1 \mathrm{~Hz}$, the duty ratio is 
$25 \%, 50 \%$, and $75 \%$, the corresponding surface roughness value and material removal amount are $R a 45 \mathrm{~nm}$ and $49.34 \mathrm{mg}, R a 35 \mathrm{~nm}$ and $35.5 \mathrm{mg}$, and $R a 35.7 \mathrm{~nm}$ and $36.51 \mathrm{mg}$, respectively.

The experimental results are shown in Figure 10, when the $10 \mathrm{~Hz}$ rectangular wave pulse voltage with a duty ratio of $25 \%, 50 \%$, and $75 \%$ is used. From the amount of material removal, it can be seen that after two min of P-EMAF processing, the highest material removal rate was obtained by using pulse voltage with duty ratio of $25 \%$, and it is obviously higher than that of duty ratios of $50 \%$ and $75 \%$. From the surface roughness, after eightminute MAF processing, the difference of the average surface roughness values under the three conditions becomes smaller, and a relatively smooth surface is obtained. The final experimental results show that when the frequency is $10 \mathrm{~Hz}$, the duty ratio is $25 \%, 50 \%$ and $75 \%$, the corresponding surface roughness value and material removal amount is $R a$ $46.3 \mathrm{~nm}$ and $60.01 \mathrm{mg}$, $R a 41 \mathrm{~nm}$ and $38.18 \mathrm{mg}$, and $R a 37.3 \mathrm{~nm}$ and $34.72 \mathrm{mg}$, respectively.

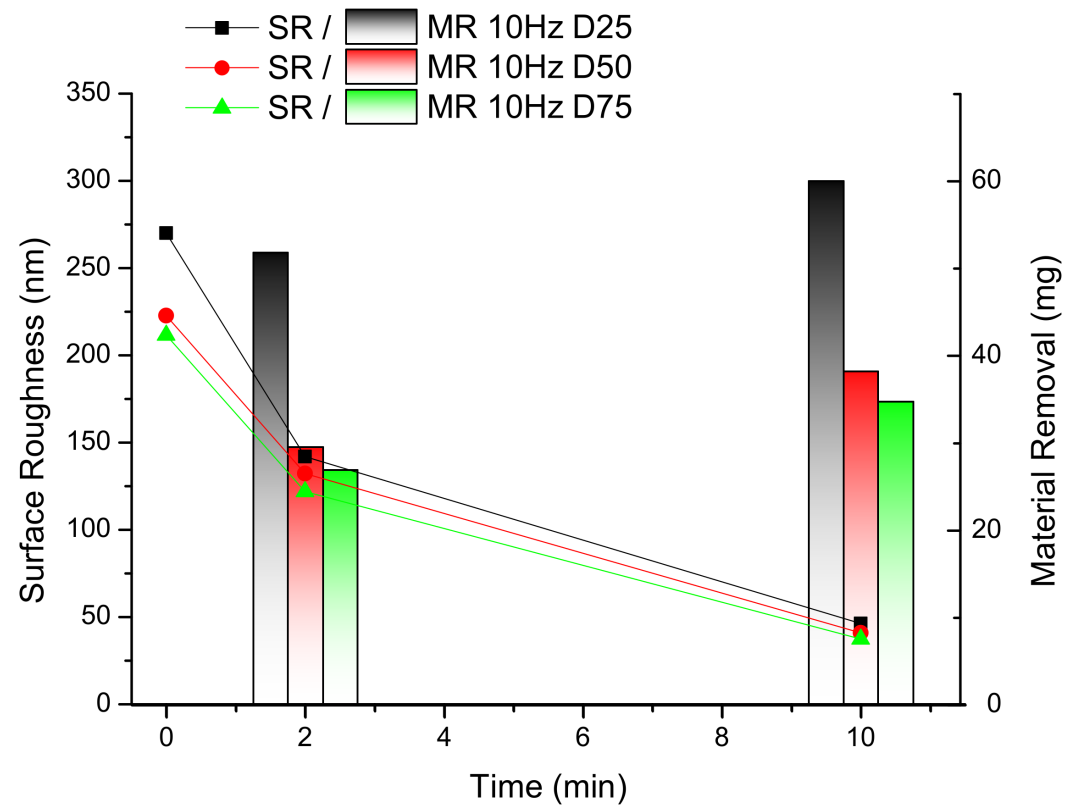

Figure 10. Experimental results when frequency is $10 \mathrm{~Hz}$.

Compared with the experimental results, when the frequency is $1 \mathrm{~Hz}$, the final average surface roughness value corresponding to the same duty ratio is better than that of $10 \mathrm{~Hz}$.

When the frequency is increased to $100 \mathrm{~Hz}$, the experimental results of different duty ratios are shown in Figure 11. From the perspective of the change rate of the surface roughness value, compared with the frequency of $1 \mathrm{~Hz}$ and $10 \mathrm{~Hz}$, after the two-minute P-EMAF processing, the decrease rate of average surface roughness value is obviously slower. After two min of P-EMAF processing, the material removal corresponding to the duty ratio of $25 \%, 50 \%$, and $75 \%$ is $55.75 \mathrm{mg}, 34.63 \mathrm{mg}$, and $29.82 \mathrm{mg}$, respectively.

The average surface roughness values after two-minute P-EMAF processing corresponding to duty ratios of $25 \%, 50 \%$, and $75 \%$ are $R a 225.3 \mathrm{~nm}, R a 159.7 \mathrm{~nm}$, and $R a 150 \mathrm{~nm}$, respectively. At the frequency of $100 \mathrm{~Hz}$, the surface roughness value after two min of P-EMAF processing is inferior to that of $1 \mathrm{~Hz}$ and $10 \mathrm{~Hz}$. After $10 \mathrm{~min}$ of processing, the average surface roughness value and material removal amount corresponding to the duty ratio of $25 \%, 50 \%$, and $75 \%$ is $R a 59.7 \mathrm{~nm}$ and $65.78 \mathrm{mg}, R a 41.7 \mathrm{~nm}$ and $41.98 \mathrm{mg}$, and $R a$ $54.7 \mathrm{~nm}$ and $37.95 \mathrm{mg}$, respectively.

In order to find out the reason for the surface deterioration, the surface morphology observed after P-MAF processing was analyzed. The reason for the unsatisfactory surface roughness value is presumed to be the occurrence of pitting corrosion after the P-EMAF processing, as shown in Figure 12. 


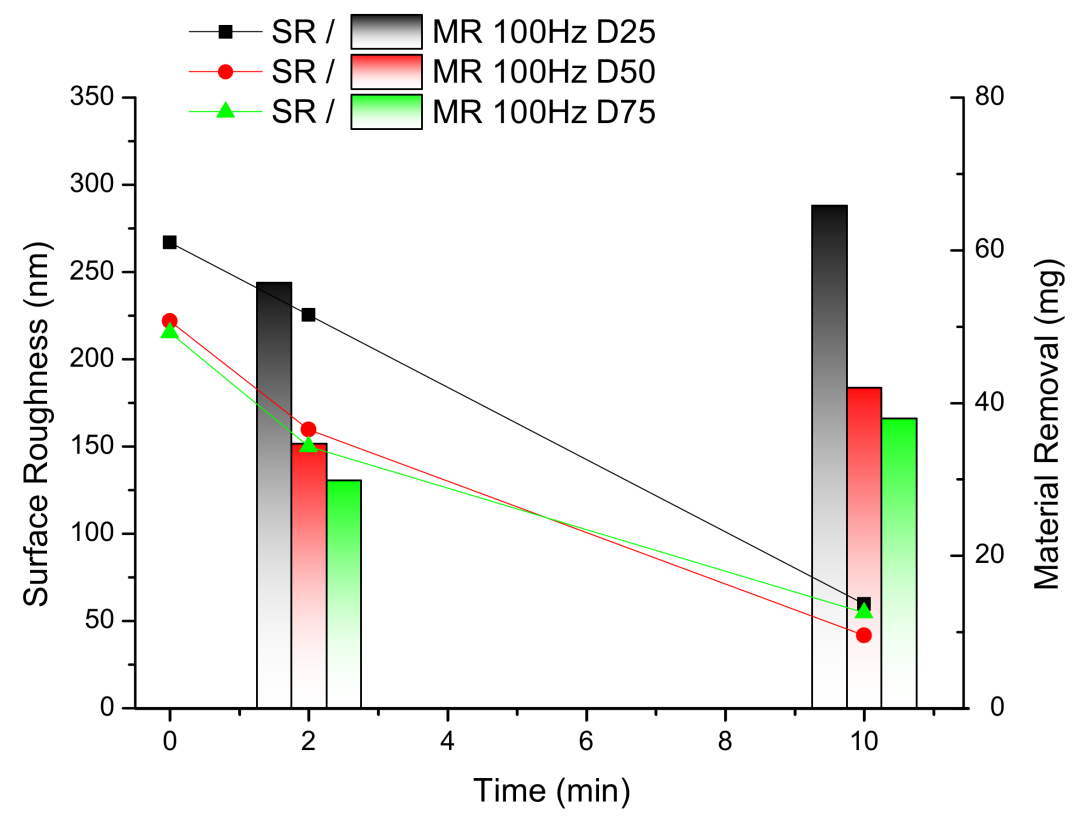

Figure 11. Experimental results when frequency is $100 \mathrm{~Hz}$.

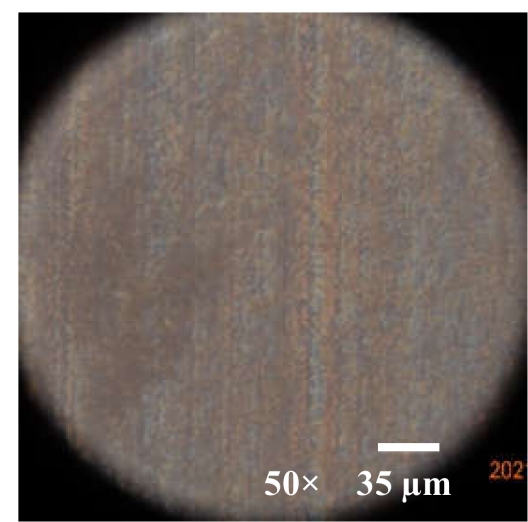

(a)

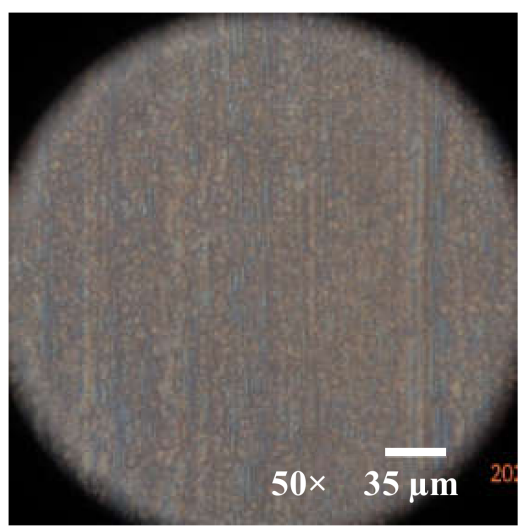

(b)

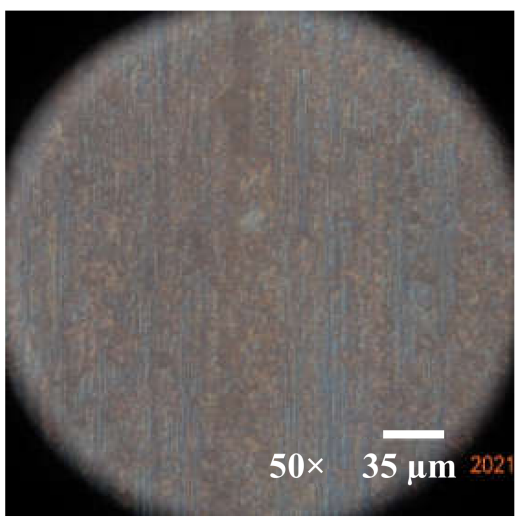

(c)

Figure 12. Surface morphology after two-minute P-EMAF processing when frequency is $100 \mathrm{~Hz}$. (a) duty ratio of $25 \%$; (b) duty ratio of $50 \%$; (c) duty ratio of $75 \%$.

It can be seen from the figure that when the frequency is $100 \mathrm{~Hz}$, after two min of P-EMAF processing, serious pitting corrosion appears. The occurrence of pitting corrosion causes the surface to be rough, and excessive pitting is not conducive to sufficient surface finishing by the MAF process. This also causes the final surface roughness value to be worse than that at the frequency is $1 \mathrm{~Hz}$ and $10 \mathrm{~Hz}$.

The experimental results are shown in Figure 13 when the frequency is $1 \mathrm{kHz}$. From the amount of material removal, after two min of P-EMAF processing, the material removal amount corresponding to the duty ratio of $25 \%, 50 \%$, and $75 \%$ is $67.38 \mathrm{mg}, 33.58 \mathrm{mg}$, and $20.79 \mathrm{mg}$, respectively. Based on the four sets of experimental results, when the duty ratio is $25 \%$, after two-minute P-EMAF processing, the order of material removal amount at different frequencies from high to low is $1 \mathrm{kHz} 67.38 \mathrm{mg}$, $100 \mathrm{~Hz} 55.75 \mathrm{mg}, 10 \mathrm{~Hz} 51.83 \mathrm{mg}$, and $1 \mathrm{~Hz} 40.85 \mathrm{mg}$. When the duty ratio is $50 \%$ and $75 \%$, the order of the corresponding material removal at different frequencies changes. When the duty ratio is $50 \%$, after twominute P-EMAF processing the order of material removal from high to low is $100 \mathrm{~Hz}$ $34.63 \mathrm{mg}, 1 \mathrm{kHz} 33.58 \mathrm{mg}, 10 \mathrm{~Hz} 29.52 \mathrm{mg}$, and $1 \mathrm{~Hz} 28.37 \mathrm{mg}$; when the duty ratio is $75 \%$, 
the amount of material removal order is $100 \mathrm{~Hz} 29.82 \mathrm{mg}, 1 \mathrm{~Hz} 28.29 \mathrm{mg}, 10 \mathrm{~Hz} 26.94 \mathrm{mg}$, and $1 \mathrm{kHz} 20.79 \mathrm{mg}$.

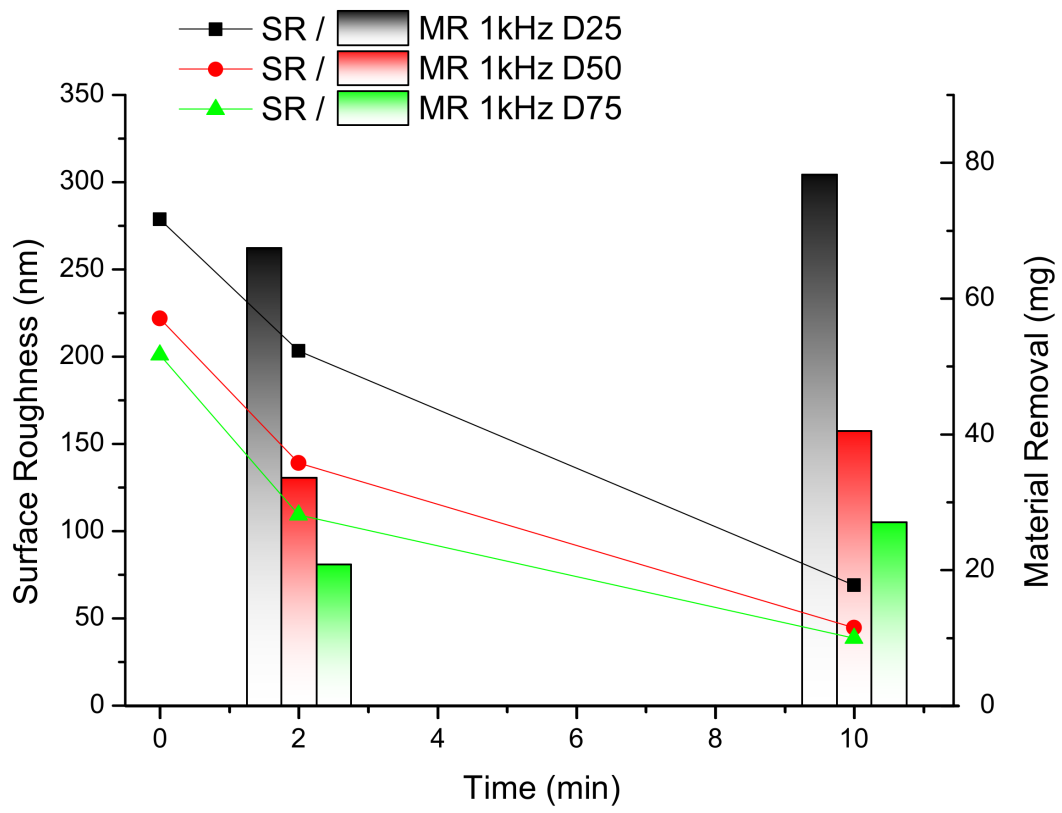

Figure 13. Experimental results when frequency is $1 \mathrm{kHz}$.

Analyzing the experimental result of material removal amount, it can be found that when the frequency is the same, the increase of the duty ratio corresponds to the decrease of the amount of material removal by the P-EMAF processing. However, when the same duty ratio is used for comparison, the order of material removal amount corresponding to frequency will become disordered. This shows that in P-EMAF processing, the impedance of electrolytic processing gap will change with the change of processing parameters because according to Equation (1), the amount of material removal is closely related to the current density that flowing through the processing area, and the current is related to the impedance of the processing gap. Therefore, during P-EMAF processing changes in frequency and duty ratio will affect the amount of material removal, and excessively violent electrolysis will cause uneven corrosion on the surface of the workpiece, thereby affecting the surface quality.

In addition, since the magnetic brush is a conductor and is in contact with the surface of the workpiece, the electrolytic reaction can also occur between the magnetic brush and the electrode during EMAF processing. If so, the shape of the magnetic brush during EMAF processing will also affect the effect of the electrolysis reaction on the workpiece.

\subsection{Observation of Iron Powder before and after Processing}

In order to prove that during EMAF processing, an electrolytic reaction also occurs on the surface of electrolytic iron powder, cylindrical magnetically permeable stainless steel particles are used as magnetic particles for EMAF processing, and the experimental conditions are shown in Table 3.

In order to facilitate the observation, SUS 304 stainless steel columnar magnetic iron powder was selected because the stainless steel iron powder will not be broken during processing and the initial surface is smooth. Since the abrasive particles will remain on the surface of the iron powder after processing and they are not easy to be completely cleaned, which will affect the observation, the abrasive slurry was not used in this experiment. During processing, electrolysis products are generated, so the iron powder was cleaned with an ultrasonic cleaning machine before observation. 
Table 3. Experimental conditions for iron powder observation.

\begin{tabular}{cc}
\hline Item & Experimental Conditions \\
\hline Workpiece & SUS 304 stainless steel plane $(100 \times 100 \times 1 \mathrm{~mm})$ \\
Electrolytic iron powders & SUS 304 stainless steel columnar magnetic iron powder \\
Electrolyte & $300 \mu \mathrm{m}, 0.5 \mathrm{~g}$ \\
Processing voltage & $\mathrm{NaNO}_{3} 20 \% \mathrm{wt}$ \\
Working gap & $8 \mathrm{~V}$ \\
Stage feed speed & $1 \mathrm{~mm}$ \\
Tool rotation speed & $5 \mathrm{~mm} / \mathrm{s}$ \\
Processing time & $450 \mathrm{rpm}$ \\
& $10 \mathrm{~min}$ \\
\hline
\end{tabular}

As shown in Figure 14, the iron powder before and after EMAF processing was observed by Scanning Electron Microscope (SEM). As shown in Figure 14a, the edges of the iron powder before processing are sharp; after processing, pitting appears on some of the iron powder particles and the edges where the corrosion occurs are rounded and small pits appear. This proves that during EMAF processing, the electrolytic reaction acts on the surface of the workpiece and the surface of the iron powder of the magnetic brush at the same time. Therefore, the shape of the magnetic brush will also affect the electrolytic reaction during EMAF processing. For example, as the processing progresses, the friction between the magnetic brush and the workpiece surface and the agitation of the electrolyte will cause the shape of the magnetic brush to change, resulting in a change in distance between the iron powder in the magnetic brush and the electrode. The change of the distance will cause the change of the impedance between magnetic brush and electrode, and the impedance determines whether the potential difference is sufficient for the electrolysis reaction to occur. If the amount of iron powder is too much, it will cause the iron powder to directly contact the electrode and cause a short circuit.

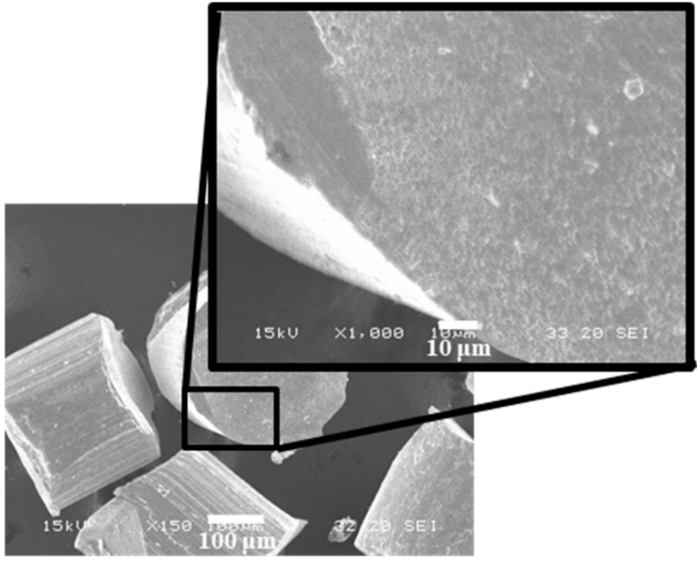

(a)

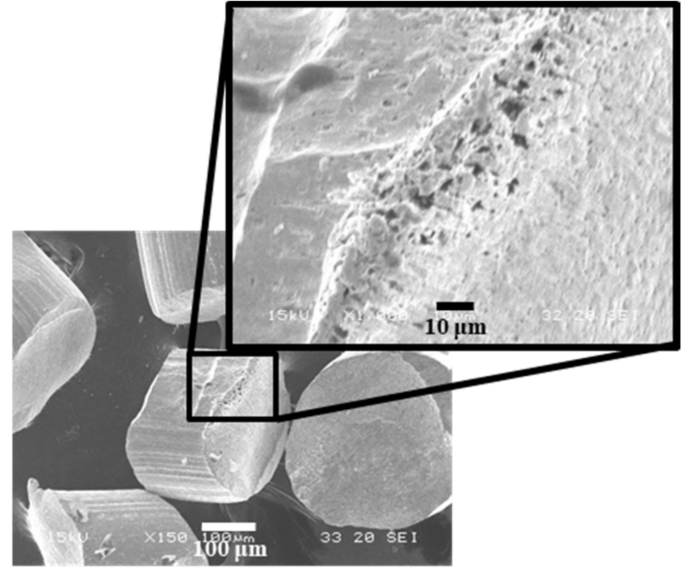

(b)

Figure 14. Observation of iron powder morphology before and after EMAF processing. (a) Before EMAF processing; (b) After EMAF processing.

\subsection{Comparison between P-EMAF Processing and MAF Processing}

In order to further evaluate the processing performance of the P-EMAF process, the MAF processing experiment was carried out under the same conditions, and the two processes were analyzed and compared. The experimental conditions of MAF are shown in Table 4. 
Table 4. MAF experimental conditions.

\begin{tabular}{cc}
\hline Item & Experimental Conditions \\
\hline Workpiece & SUS 304 stainless steel plane $(100 \times 100 \times 1 \mathrm{~mm})$ \\
Electrolytic iron powders & $330 \mu \mathrm{m}, 0.5 \mathrm{~g}$ \\
Abrasives particles & WA\#8000 \\
Cutting fluid & Water soluble (Type 1: EMAF processing conditions), \\
Electrolyte & Oily (Type 2: traditional MAF processing conditions) \\
Working gap & $\mathrm{NaNO}_{3} 20 \% \mathrm{wt}$ (Type 1: EMAF processing conditions) \\
Stage feed speed & $1 \mathrm{~mm}$ \\
Tool rotation speed & $5 \mathrm{~mm} / \mathrm{s}$ \\
Processing time & $450 \mathrm{rpm}$ \\
& $10 \mathrm{~min}$ \\
\hline
\end{tabular}

The MAF experiment is divided into two types; type one is under the conditions of EMAF processing, the workpiece and the processing tools are immersed in the electrolyte, and the water-based cutting fluid is used at these conditions; type two is the traditional MAF processing conditions, at this time there is no electrolyte, and oily cutting fluid is used.

Because the optimal surface roughness value appears when the frequency is $1 \mathrm{~Hz}$ and the duty ratio is $50 \%$, P-EMAF processing of a frequency of $1 \mathrm{~Hz}$ with duty ratios of $25 \%, 50 \%$, and $75 \%$ were used to be compared with the MAF processing under the two experimental conditions. The experimental results are shown in Figure 15. Firstly, from the experimental results, comparing the MAF processing under the two conditions, it can be seen that under the EMAF processing conditions, both the average surface roughness value and the amount of material removal are inferior to the MAF processing under traditional conditions. Therefore, it can be inferred that the processing performance of the MAF process is affected by the electrolyte because the electrolyte is agitated by the rotating composite processing tool during processing, which will cause the abrasive particles to be dispersed in the electrolyte, thereby affecting processing efficiency.

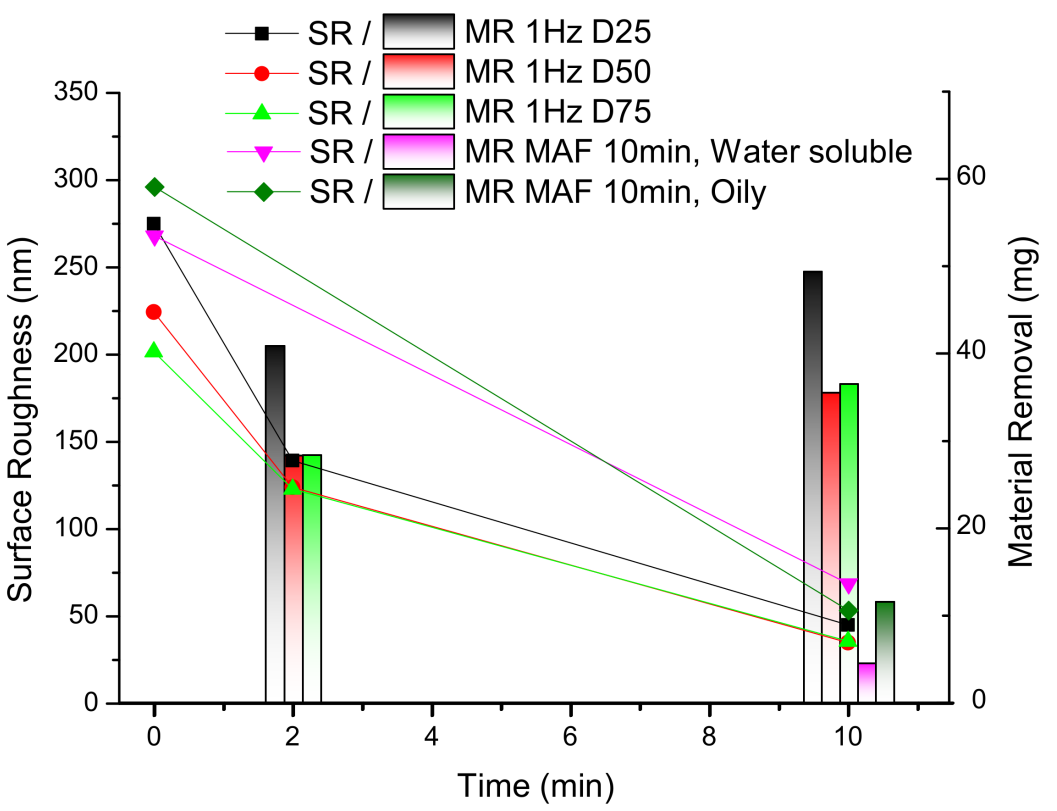

Figure 15. P-EMAF processing and MAF processing comparison experimental results.

Then, comparing MAF processing with P-EMAF processing, it can be seen that after two-minute P-EMAF and eight-minute MAF processing, the surface roughness value and material removal are better than that of traditional MAF processing because the twominute P-EMAF processing in the early stage accelerates the flattening of the surface of the workpiece and is conducive to the MAF processing in the later stage. 
The 3D surface topography pictures are shown in Figure 16. When the frequency of the rectangular wave pulse voltage is $1 \mathrm{~Hz}$, the duty ratio is $50 \%$. It can be seen from Figure 16a that there are deep grooves on the surface before processing. After two-minute P-EMAF processing, the surface becomes flat, and after eight min MAF processing, the surface becomes smooth. After $10 \mathrm{~min}$ of MAF processing, there will be deeper grooves remaining on the surface, as shown in Figure 16b,c.

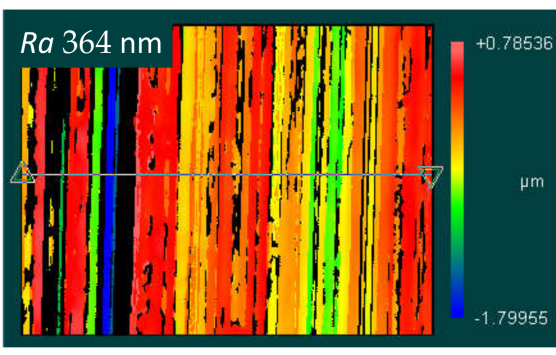

Before finishing

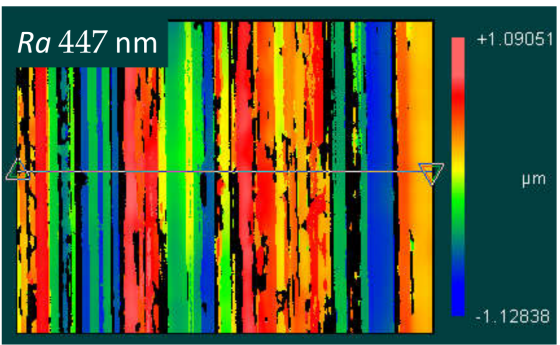

Before finishing

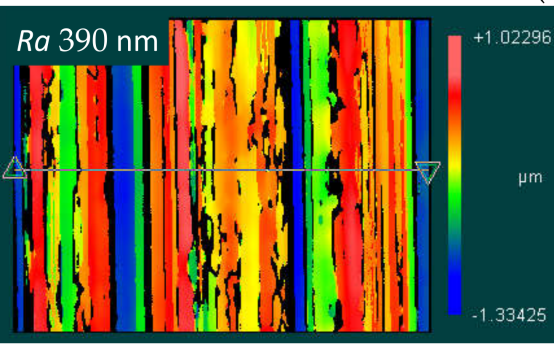

Before finishing

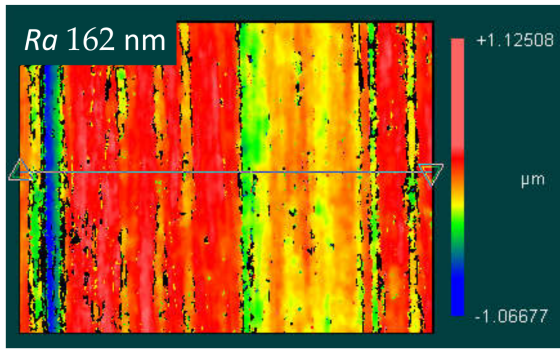

After two-minute P-EMAF processing

(a)

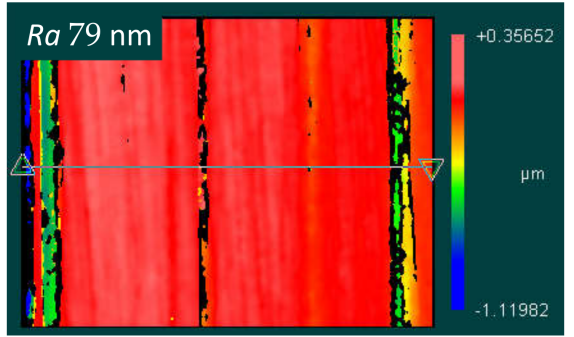

After 10-minute MAF processing (Cutting fluid: Oily)

(b)

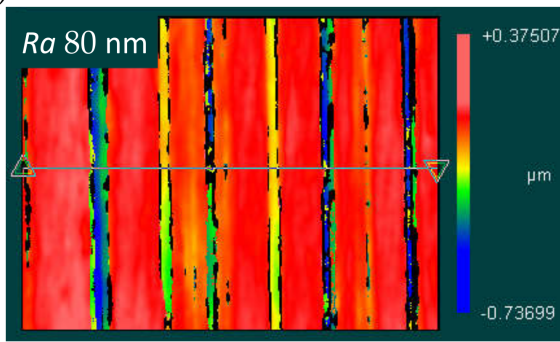

After 10-minute MAF processing

(Cutting fluid: Water soluble)

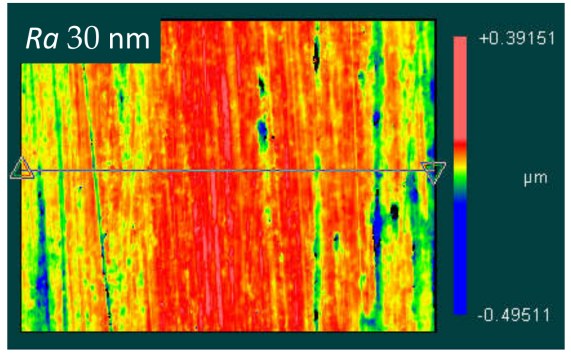

After two-minute P-EMAF + eightminute MAF processing

(c)

Figure 16. 3D surface topography before and after finishing. (a) P-EMAF processing; (b) traditional MAF processing; (c) MAF processing under EMAF processing experimental conditions.

\section{Discussion}

Through a series of exploratory experiments, the feasibility of using the P-EMAF process to finish the surface of a SUS 304 stainless steel plane plate was proved. Additionally, the processing efficiency of the P-EMAF process was shown to be higher than that of the MAF process. Moreover, through further analysis of experimental phenomena and results, the EMAF processing mechanism was further clarified. By observing the shape of iron powder before and after processing, the electrolytic reaction also acting on the iron powder in the magnetic brush during EMAF processing was confirmed. Finally, by analyzing the experimental data under different frequencies and duty ratios during $\mathrm{P}$ EMAF processing, the influencing factors of the impedance in the electrolytic processing gap of P-EMAF processing include controllable factors such as frequency and duty ratio, as 
well as the uncontrollable factors such as electrolysis products, gas, and magnetic brush shape generated during processing.

\section{Conclusions}

After a series of exploratory experiments to investigate the finishing characteristics for finishing SUS 304 stainless steel by P-EMAF process, the conclusions are as follows:

1. Through a series of exploratory experiments, it is proved that the compound processing tool (four magnetic poles arranged in the same direction and a cross electrode) can be used for the finishing of SUS 304 stainless steel by the P-EMAF process.

2. In this study, compared with the traditional MAF process under the same experimental conditions, the P-EMAF process can obtain better surface roughness values and a higher material removal amount.

3. In this experiment, during EMAF processing, the electrolytic reaction not only occurs between the workpiece surface and the electrode but also occurs between the iron powder in the magnetic brush and the electrode.

4. In this study, the best experimental condition is the $U_{r m s} 6 \mathrm{~V}$ pulse voltage (rectangular wave) with $1 \mathrm{~Hz}$ and duty ratio of $50 \%$ is used for P-EMAF processing, and the $\mathrm{NaNO}_{3}$ aqueous solution concentration is $20 \% \mathrm{wt}$.

Author Contributions: Project administration, Y.Z.; experiments B.X., M.T. and Y.Z.; data curation, B.X., M.T. and Y.Z.; writing-original draft preparation, B.X., Y.Z.; writing-review and editing, B.X. and Y.Z.; Simulation, B.X. All authors have read and agreed to the published version of the manuscript.

Funding: This research received no external funding.

Institutional Review Board Statement: Not applicable.

Informed Consent Statement: Not applicable.

Data Availability Statement: Not applicable.

Conflicts of Interest: The authors declare no conflict of interest.

Sample Availability: Not available.

\section{References}

1. Shinmura, T.; Aizawa, T. Development of plane magnetic abrasive finishing apparatus and its finishing performance (2nd Report, Finishing apparatus using a stationary type electromagnet). J. Jpn. Soc. Prec. Eng. 1988, 54, 928-933. (In Japanese) [CrossRef]

2. Shinmura, T.; Takazawa, K.; Hatano, E. Study on magnetic abrasive process (Application to plane finishing). Bull. Jpn. Soc. Precis. Eng. 1985, 19, 289-294.

3. Shinmura, T. Study on free-form surface finishing by magnetic abrasive finishing process (1st Report, Fundamental experiments). Trans. Jpn. Soc. Mech. Eng. 1986, 53, 202-208. (In Japanese) [CrossRef]

4. Shinmura, T.; Takazawa, K.; Hatano, E.; Matsunaga, M. Study on magnetic abrasive finishing. CIRP Ann. Manuf. Technol. 1990, 39, 325-328. [CrossRef]

5. Vahdati, M.; Rasouli, S. Evaluation of Parameters Affecting Magnetic Abrasive Finishing on Concave Freeform Surface of Al Alloy via RSM Method. Adv. Mater. Sci. Eng. 2016, 257, 505-510. [CrossRef]

6. Zou, Y. Internal finishing of micro tubes by the magnetic abrasive finishing. J. Jpn. Soc. Abras. Technol. 2012, 56, 86-89. (In Japanese)

7. Zou, Y.; Shinmura, T. Study on magnetic field-assisted machining process for internal finishing using magnetic machining jig. Key Eng. Mater. 2004, 257, 505-510. [CrossRef]

8. Amineh, S.K.; Tehrani, A.F.; Mohammadi, A. Improving the surface quality in wire electrical discharge machined specimens by removing the recast layer using magnetic abrasive finishing method. Int. J. Adv. Manuf. Technol. 2013, 66, $1793-1803$.

9. Sun, X.; Zou, Y. Development of magnetic abrasive finishing combined with electrolytic process for finishing SUS304 stainless steel plane. Int. J. Adv. Manuf. Technol. 2017, 92, 3373-3384. [CrossRef]

10. Shinmura, T. Study on plane magnetic abrasive finishing (3rd Report on the finishing characteristics of non-ferromagnetic substance). J. Jpn. Soc. Prec. Eng. 1989, 55, 1271-1276. (In Japanese) [CrossRef]

11. Shinmura, T.; Takazawa, K.; Hatano, E. Study on magnetic abrasive process (Process principles and finishing possibility). Bull. Jan. Soc. Precis. Eng. 1985, 19, 54-55.

12. Shinmura, T.; Takazawa, K.; Hatano, E. Study on magnetic abrasive process (1st Report)—Process principles and finishing possibility. Precis. Eng. 1986, 52, 851. (In Japanese) [CrossRef] 
13. Lohrengel, M.M.; Rataj, K.P.; Münninghoff, T. Electrochemical Machining-mechanisms of anodic dissolution. Electrochim. Acta 2016, 201, 348-353. [CrossRef]

14. McGeough, J.A. Principles of Electrochemical Machining; Chapman and Hall: London, UK, 1974.

15. Rajurkar, K.P.; Zhu, D.; McGeough, J.A.; Kozak, J.; De Silva, A. New Development in electro-chemical machining. CIRP Ann.-Manuf. Technol. 1999, 48, 567-579. [CrossRef]

16. Labib, A.W.; Keasberry, V.J.; Atkinson, J.; Frost, H.W. Towards next generation electrochemical controllers: A fuzzy logic control approach to ECM. Expert Syst. Appl. 2011, 38, 7486-7493. [CrossRef]

17. Rajurkar, K.P.; Sundaram, M.M.; Malshe, A.P. Review of electrochemical and electrodischarge machining. Procedia CIRP 2013, 6 , 13-26. [CrossRef]

18. Zou, Y.; Xing, B.; Sun, X. Study on the magnetic abrasive finishing combined with electrolytic process-Investigation of machining mechanism. Int. J. Adv. Manuf. Technol. 2020, 108, 1675-1689. [CrossRef]

19. Xing, B.; Zou, Y. Investigation of Finishing Aluminum Alloy A5052 Using the Magnetic Abrasive Finishing Combined with Electrolytic Process. Machines 2020, 8, 78. [CrossRef]

20. Harada, S.; Natsu, W. Study on Sensitivity of Gap-width Detection with Peak Current in Pulse ECM. In Proceedings of the 12th euspen International Conference, Stockholm, Sweden, 4-8 June 2012; Volume 6.

21. Rajurkar, K.P.; Kozak, J.; Wei, B.; McGeough, J.A. Study of Pulse Electrochemical Machining Characteristics. CIRP Ann. 1993, 42, 231-234. [CrossRef]

22. McGeough, J.A.; Barker, M.B. Electrochemical machining. Int. J. Chemtech. Res. 1991, 9, 536-542.

23. Rebecca, J.L.; Atanas, I. Electrochemical micromachining: An introduction. Adv. Mech. Eng. 2016, 8, 1-13.

24. Natsu, W.; Kunimi, T. Analysis of ECM phenomena with equivalent circuit for electrolysis. Int. J. Electr. Mach. LJEM 2009, $15,45-50$

25. Natsu, W. Basic Theory and Actual Situation of Electrochemical Machining. J. Jpn. Soc. Prec. Eng. 2015, 81, 317-322. [CrossRef]

26. Natsume, M.; Shinmura, T. Study on the mechanism of plane magnetic abrasive finishing process-elucidation of normal force characteristics. Trans. Jpn. Soc. Mech. Eng. 2008, 74, 212-218. [CrossRef]

27. Shinmura, T.; Takazawa, K.; Hatano, E.; Aizawa, T. Study on magnetic abrasive process-finishing characteristics. Bull. JSPE 1984, $18,347$.

28. Daintith, J. A Dictionary of Physics, 6th ed.; Oxford University Press: Oxford, UK, 2009.

29. Sylvanus, P.T. Calculus Made Easy; Macmillan International Higher Education: London, UK, 2020; p. 185. 